\title{
ROUNDABOUT AS AN ATERNATIVE FOR SIGNALIZED INTERSECTION AT SITRA JUNCTION, COIMBATORE (EAST)
}

\author{
P Indhiradevi \\ Assistant Professor, \\ KPR Institute of Engineering and Technology, Coimbatore \\ P. Ranjith kumar \\ Assistant Professor, \\ Panimalar Engineering College, Chennai \\ M. Mary Cecily Amala, S. Kowsalya \\ UG Student, \\ KPR Institute of Engineering and Technology, Coimbatore
}

\begin{abstract}
The roundabouts are a kind of intersection that is characterized by an especial geometry derived on the way their branches are communicated by a ring-shaped road where circulation is established in one-way, rounding a central obstacle. Traffic conflicts at sitra junction increases due to rapid growth of city and due to development of colleges, hospitals, international airport, etc. So to overcome the problems in signalized intersections an roundabout is designed according to IRC standards. By providing roundabouts the travelling comfort is made better and more consistent as there is no need to stop for crossing traffic at intersection. Pedestrian bridge is provided to separate the road users and pedestrians using the intersection. Since the speed is slow at roundabouts the accidents rate reduces and there is no need of implementing traffic signals to control the vehicle movements. The roundabouts are economical in aspects of design and construction and they reducing pollution from stopping vehicles.
\end{abstract}

Keywords-Roundabouts, Pedestrian bridge, accident, intersection, Traffic

\section{INTRODUCTION}

During the past decade major cities have under gone hazard growth of industrialization, urbanization of country, and Coimbatore is not exception for that. Traffic is increasing day by day, so it is almost impossible for traffic police to control the traffic manually at the intersection. Although the signals have been provided on both intersection but the traffic congestion has not been reduced effectively. In order to improve the traffic conditions as well as the aesthetic view at the said intersections, we suggest to design the roundabout at these intersections to reduce traffic congestion keeping in view high traffic and conditions favouring the roundabout. A signalized intersection in SITRA junction causes more conflicts and accidents during peak hours due to heavy traffic flow, so a un-signalized intersection (roundabout) is proposed to reduce these problem. A Roundabout is a type of circular intersection with a specific design and traffic control features. Roundabouts can be designed to suit most site conditions, traffic volumes, speeds, and all road user requirements. This gives the benefits of safety and efficiency in an unsignalized intersection. Safety is achieved by reduced speed within the roundabout and efficiency by high directness in time and distance or minimal delays for all users.

\section{LITERATURE REVIEW}

Weiqiwang,et al (2012) used the concepts of reserve capacity to create a new method to calculating the capacity of roundabouts. The substance of this concept is that when the stream of vehicles at weaving section achieves the capacity and become the bottleneck of the roundabouts, the sum of all flows at weaving sections in the all directions is the capacity of roundabouts. This methods is calculated using selection of roundabouts of interest and gap acceptance theory and the capacity of weaving sections.

Dongxi Zheng, David (2012) are explained concept of standard roundabout is a new type of intersection designed to reduce crash risk and lower crash severity. The circular intersections, is applied at roundabout to eliminate all crossings vehicular conflicts. Additionally, approaches to a roundabout are deflected to a certain degree to reduce approaching speed and facilitate weaving and merging managers between entering and circulating vehicles, avoiding direct collisions. Further, with the yield-to-circulating rule at a roundabout 


\section{International Journal of Engineering Applied Sciences and Technology, 2019 \\ Vol. 4, Issue 2, ISSN No. 2455-2143, Pages 130-134 \\ Published Online June 2019 in IJEAST (http://www.ijeast.com)}

entrance, roundabout aim to safer driving experience when compared to conventional intersections.

Au Zong Than, Michael kyte, Hongchao Liu (2009) are investigated about Video detection system provide a way to automate data collection tasks. This feature describes a unique use of video detection system to main-street through vehicle and measure speeds at two-way, stopcontrolled (TWSC) intersections.

Said Easa et al (2006) are used the concept of Multi objective involved, the design process is iterative and time consuming. A minor change in the geometric can result in significant changes in system performance. The objectives as design consistency and operational efficiency. The input geometric data to the model can be easily obtained from an aerial photograph of selected site using GIS software.

\section{METHODOLOGY}

Traffic surveys at intersection were conducted by manual method. For this method we had first studied about the procedure and collected the required information \& forms, then we performed traffic survey at the intersection. Traffic survey was conducted by splitting three field observers at each leg. One observer was appointed to count overall vehicle volume passing through fixed point, while other two were appointed to count left and right turning vehicle volume. Six surveys were carried out at peak hours at sitra junction. The traffic flow mainly includes cars, auto rickshaw, two wheelers, bus, trucks and other light commercial vehicles such as tempos. From survey performed, we preferred average survey data from for design purpose as it had maximum traffic volume amongst all surveys then calculations of traffic intensity by multiplying with their respective Passenger Car Unit (PCU) had been done. After this we have carried out calculation for weaving length, entry, exit radius etc. and other factors such as radii of Central Island were referred from IRC 65. Obtained data were impart to AutoCAD Civil 3D to design roundabout for specified condition.

\section{AERA STUDY}

The location selected for designing the roundabout is situated at sitra junction, Coimbatore (east), Tamilnadu is pretty much crowded area due to hospitals, airports and colleges situated in this region. At the intersection there are four roads namely Kalapatti road, Avinashiroad, Coimbatore Airport road, Peelamedu road, which are major district roads. In fig. No. Exact location of the junction is given. Due to rapid growth and development population of this area has been increased in last decade which also leads to increase in number of vehicles and traffic congestion. All four roads have traffic signals of $30 \mathrm{sec}$ allowance which is not efficiently handling the traffic so to overcome this problem we think that roundabout will be more efficient option and hence we are designing the roundabout for said intersection.

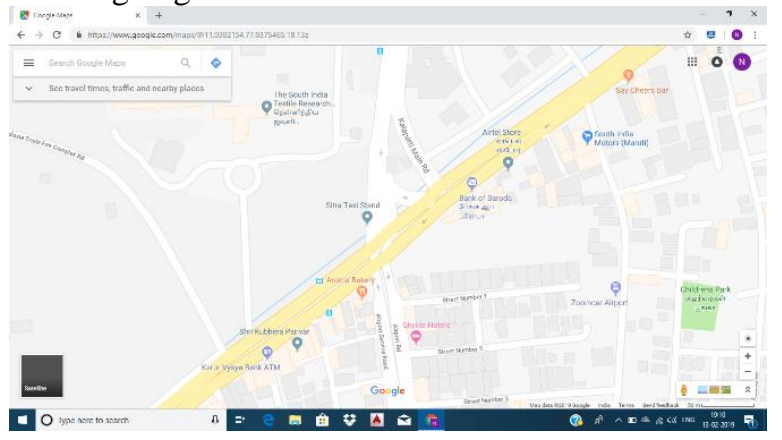

Fig. No 4.1. Location plan source: Google maps

\section{DATA COLLECTION}

To design roundabout we have carried out surveys on peak hours and non-peak hour's basis. On six different respectively, so that we can cover traffic on weekdays as well as weekends. The survey reports are represented in the bar graph as shown below.

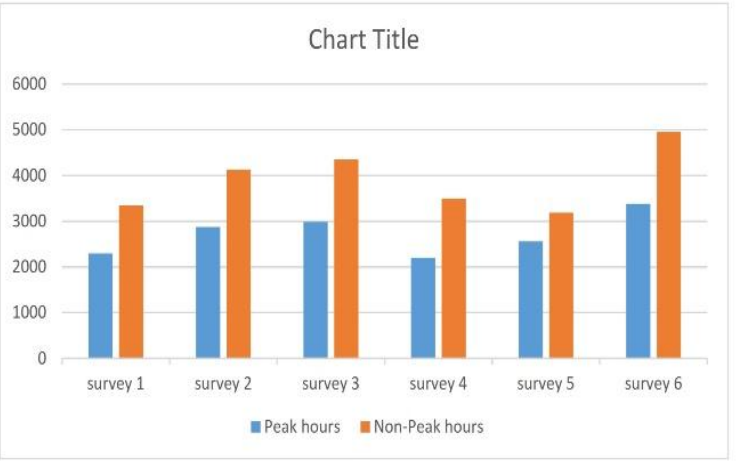

Fig. No.5.1: Representation of Traffic Survey

In Fig. No.5. 1 we can take average survey had maximum number of vehicles so it is more favorable to take this data for design purpose so that designed roundabout can handle traffic more effectively.

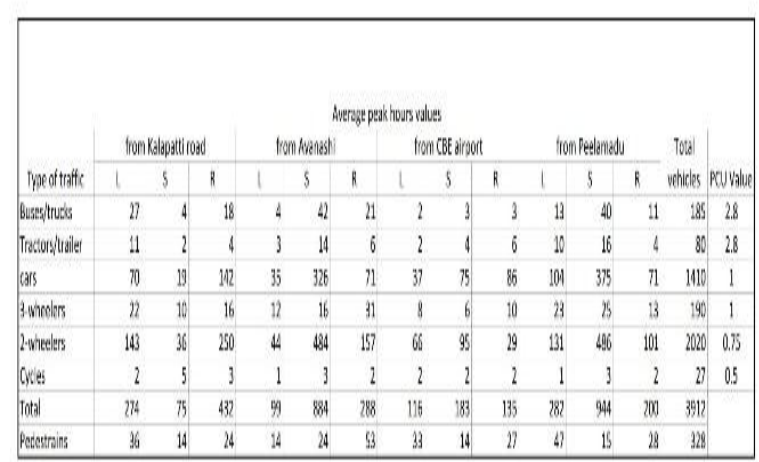

Table5.1 Survey data 


\section{CONDITIONS AT}

\section{INTERSECTION AND THEIR SUTABILITY}

As per IRC 65, a roundabout can handle 3000 vehicles per hour from all leg efficiently. At study area i.e. sitra junction we did surveys, 6 in peak hours and remaining 6 in non-peak hours, on the basis of this surveys we can firmly say that this intersection does not cross this permissible limit so by considering this point, we can say that this intersection is suitable for roundabout.

Also in IRC it is mentioned that if traffic volume with more than $30 \%$ right turning then roundabout is suitable in such cases, so we thus calculate total volume of right turning traffic, and it is more than $30 \%$ on each leg following calculation from survey 2 (morning), which makes our above statement valid Leg $\mathrm{A}=$ (right turning volume $) /($ overall volume $)=407 / 784 \times 100=51.91 \%$ Similarly,

$$
\begin{aligned}
& \text { Leg B }=297 / 1257 \times 100=23.62 \% \\
& \text { Leg C }=142 / 416 \times 100=34.13 \% \\
& \text { Leg D }=200 / 1410 \times 100=14.17 \%
\end{aligned}
$$

So also from this point of view the intersection is suitable for roundabout.

Roundabout required large area for construction, the concerned intersection has major district roads which are wide enough to construct roundabout. Also all four legs have unequal volume of traffic, so this things are also suitable for roundabout. So from above points we strongly recommend roundabout at considered intersection i.e. at sitra junction.

\section{DESIGN OF ROUNDABOUT}

For designing roundabout different components of roundabout are need be design separately which are entry, exit curve, waving width, radius of central island etc. this components has been discussed already in this paper so now moves towards designing calculations and adoption for roundabout at sitra junction.

\section{a. Design speed}

For measuring speed of vehicles at selected intersection we did spot speed study by stopwatch method and the speed we took for design speed as $40 \mathrm{KMPH}$ which is also recommended by IRC 65 for urban areas.

\section{b. Shape of Central Island}

Shape of Central Island mainly depends on number and type of roads at intersection. Concerned intersection have four legs which almost 90 degrees angle to each other and also it has relatively equal traffic volume from all four legs so we going to adopt Circular shaped central island.

\section{c. Entry radius $\left(e_{1}\right)$}

Entry radius depends upon design speed, and in this case we had already adopt design speed as $30 \mathrm{KMPH}$. Suggested value for e1 as per IRC 65-1976, page No. 9 table No. 1 is 15 meters to 25 meters so take $\mathrm{e}_{1}=15$ meters

\section{d. Exit radius}

In IRC it is mentioned that Exit radius should slightly more than entry radius so that driver can increase their speed at exit the recommended value is 1.5 times of $\mathrm{e}_{1} \mathrm{So}$, exit radius $=1.5 \times 15=22.5$ meters.

\section{e. Radius of Central Island}

Radius of central island should be bigger than radius at entry generally it is adopted as 1.33 times of entry radius. Which is also mentioned in IRC 65-1967. So, Radius of central island $=1.33 \times 15=19.95$ meters say 20 meters.

\section{f. Weaving length}

The weaving length determines the ease with which the traffic can merge and diverge. The weaving length decided on the basis of factors such as the width of weaving section, the average width at entry, total traffic and the proportion of weaving traffic in it. Weaving length from page No. 10 from IRC 65-1967 For design speed $30 \mathrm{KMPH}$ minimum suggested value for weaving length is 30 meters. So, take weaving length $=30$ meters

\section{g. Weaving angle}

Weaving angle should be as small as possible but should not be less than 15 degrees.

So take weaving angle $=45$ degree.

\section{h. Width of carriageway at entry and exit}

The carriageway width of the intersection leg is governed by the design year traffic entering and leaving the intersection. Since the maximum width of carriageway of the concerned intersection is 16.76 meters $\approx(17$ meters $)$.

\section{i. Width of Non Weaving section $\left(\mathbf{e}_{2}\right)$}

IRC 65-1967, on page No. 10 recommends that the width of non-weaving section should be equal to the widest single entry into the roundabout and should generally be less than width of weaving section. Therefore, $\mathrm{e}_{2}=10$ meters (from above point $\mathrm{H}$ )

\section{j. Width of weaving section (w)}

Width of waving section of roundabout should be one traffic lane wider ( 3.5 meter) then the mean entry width. i.e.

Mathematically, $\mathrm{w}=\left(\mathrm{e}_{1}+\mathrm{e}_{2}\right) / 2+3.5=16$ meters

k. Capacity of Roundabout

\begin{tabular}{|c|c|c|c|}
\hline Approach & $\begin{array}{c}\text { Left } \\
\text { turning }\end{array}$ & $\begin{array}{c}\text { Straight } \\
\text { turning }\end{array}$ & $\begin{array}{c}\text { Right } \\
\text { turning }\end{array}$ \\
\hline $\begin{array}{c}\text { Leg A } \\
\text { (north) }\end{array}$ & 137.8 & 39.4 & 244.7 \\
\hline $\begin{array}{c}\text { Leg B } \\
\text { (east) }\end{array}$ & 49.35 & 544.9 & 135.75 \\
\hline $\begin{array}{c}\text { Leg C } \\
\text { (south) }\end{array}$ & 61.95 & 84.9 & 99.45 \\
\hline $\begin{array}{c}\text { Leg D } \\
\text { (west) }\end{array}$ & 135.6 & 631.85 & 90.95 \\
\hline
\end{tabular}


Table No.7.1: Traffic volume in PCU/hr.

The traffic in terms of PCUs from each leg is illustrated in fig No.7.1 below:

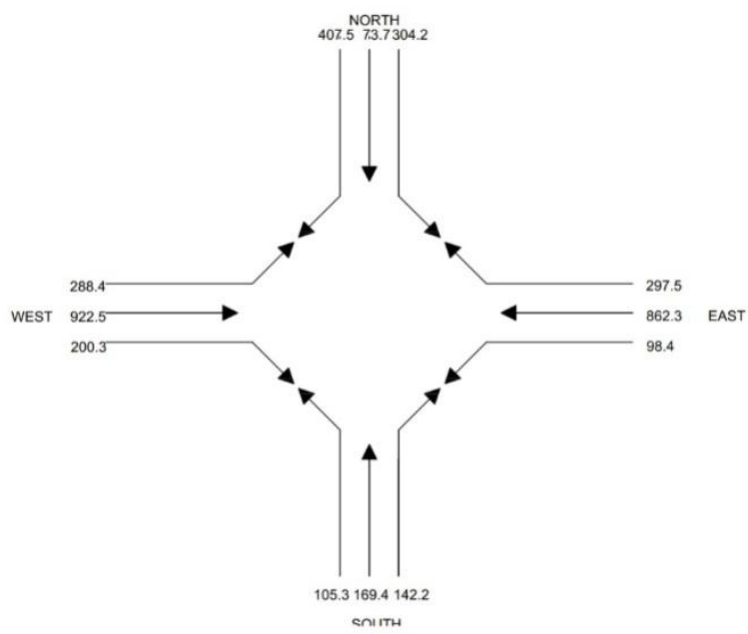

Fig No.7.2: Traffic approaching from each leg to roundabout in PCU/hr.

Fig No.7.2.1: Traffic approaching on each leg in PCU/hr.

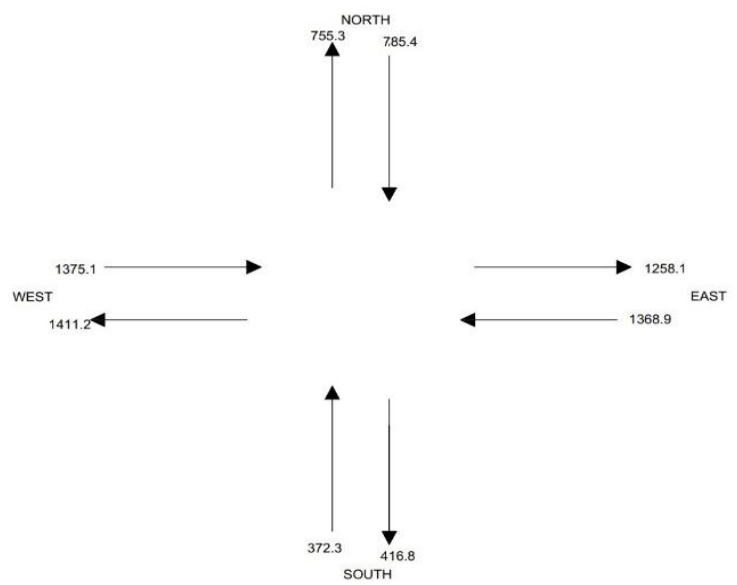

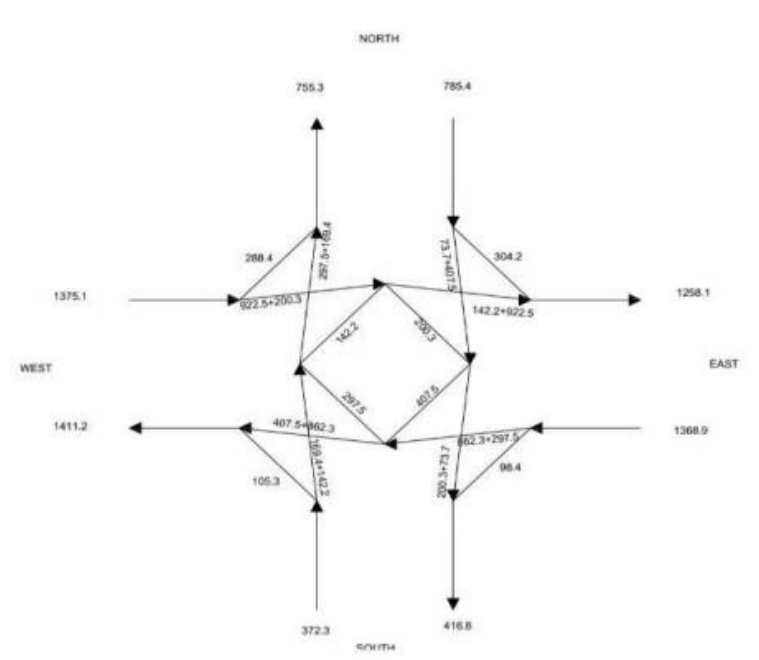

Fig No.7.3: Traffic flow is allocated to the network

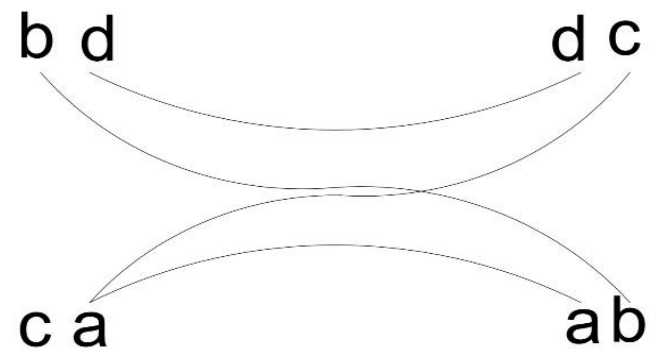

Fig No.7.4: waving traffic

Weaving traffic from east to south i.e. from Leg A to Leg C $\mathrm{a}=304.2 \mathrm{PCU} / \mathrm{hr}$.

$\mathrm{b}=(73.7+407.5)=481.2 \mathrm{PCU} / \mathrm{hr}$.

$\mathrm{c}=(142.2+992.5)=1064.7 \mathrm{PCU} / \mathrm{hr}$.

$\mathrm{d}=200.3 \mathrm{PCU} / \mathrm{hr}$.

$\mathrm{P}=(\mathrm{b}+\mathrm{c}) /(\mathrm{a}+\mathrm{b}+\mathrm{c}+\mathrm{d})$ from IRC 65-1967 Page No.12 Therefore,

$\mathrm{P}=(481.2+1064.7) /(304.2+481.2+1064.7+200.3)$

$\mathrm{P}=0.8$

Hence mathematical formula for capacity of roundabout, from IRC 65-1967 Page No.11

$\mathrm{Qp}=\{280 * \mathrm{w}[1+(\mathrm{e} / \mathrm{w})] *[1-(\mathrm{P} / 3)]\} /[1+(\mathrm{w} / \mathrm{l})]$

$\mathrm{Qp}=\{280 * 16[1+(10 / 16)] *[1-(0.8 / 3)]\} /[1+(16 / 30)] \mathrm{Qp}$ $=3554.6 \mathrm{PCU} / \mathrm{hr}$.

Similarly, weaving traffic from West to South i.e. Leg B to Leg c

$\mathrm{a}=98.4 \mathrm{PCU} / \mathrm{hr}$.

$\mathrm{b}=(862.3+297.5)=1159.8 \mathrm{PCU} / \mathrm{hr}$.

$\mathrm{c}=(200.3+73.7)=273.9 \mathrm{PCU} / \mathrm{hr}$.

$\mathrm{d}=407.5 \mathrm{PCU} / \mathrm{hr}$. 


\section{International Journal of Engineering Applied Sciences and Technology, 2019 \\ Vol. 4, Issue 2, ISSN No. 2455-2143, Pages 130-134 \\ Published Online June 2019 in IJEAST (http://www.ijeast.com)}

$\mathrm{P}=0.7$

$\mathrm{Qp}=3578.0 \mathrm{PCU} / \mathrm{hr}$.

Weaving traffic from West to North i.e. Leg B to Leg D $\mathrm{a}=105.3 \mathrm{PCU} / \mathrm{hr}$.

$\mathrm{b}=(169.4+142.2)=311.6 \mathrm{PCU} / \mathrm{hr}$.

$\mathrm{c}=(407.5+862.3)=1269.8 \mathrm{PCU} / \mathrm{hr}$.

$\mathrm{d}=142.2 \mathrm{PCU} / \mathrm{hr}$.

$\mathrm{P}=0.8$

$\mathrm{Qp}=3486.5 \mathrm{PCU} / \mathrm{hr}$.

Weaving traffic from North to East i.e. Leg D to Leg A $\mathrm{a}=288.4 \mathrm{PCU} / \mathrm{hr}$.

$\mathrm{b}=(922.5+200.3)=1122.8 \mathrm{PCU} / \mathrm{hr}$.

$\mathrm{c}=(297.5+169.4)=466.9 \mathrm{PCU} / \mathrm{hr}$.

$\mathrm{d}=142.2 \mathrm{PCU} / \mathrm{hr}$.

$\mathrm{P}=0.8$

$\mathrm{Qp}=3502.5 \mathrm{PCU} / \mathrm{hr}$.

Hence consider capacity of designed roundabout is minimum from above four Qp i.e. 3486.5 PCU/hr.

\section{RESULT}

From above calculations, capacity for Kalapatti road (Leg A) to Coimbatore airport road (Leg C) is 3554.6 $\mathrm{PCU} / \mathrm{hr}$. which is maximum from all weaving sections, capacity for Avinashi road (Leg B) to Coimbatore airport road (Leg C) is 3578.0 PCU/hr. which is minimum of all waving section, capacity for Avinashi road (Leg B) to Peelamedu road (Leg D) is 3486.5 PCU/hr.

\section{PEDESTRAIN CROSSING}

From the survey taken, the pedestrian crossing is considerably high in all four directions, so a pedestrian crossing bridge is important in this junction. For constructing a bridge in steel structure is more efficient for use and construction purpose, so a steel structure pedestrian bridge is designed using IRC recommendations.

\section{CONCLUSION}

In our study we performed surveys and accumulate traffic data which was required for designing roundabout, and after studying all necessary requirements and calculation we found that minimum capacity of designed roundabout is $3486.5 \mathrm{PCU} / \mathrm{hr}$. whereas maximum required capacity for concerned intersection is $3578.0 \mathrm{PCU} / \mathrm{hr}$. hence we can conclude that designed roundabout can efficiently handle present traffic flow as well as if in near future if there is slightly increase in rate of traffic flow, designed roundabout is capable for managing the traffic. Apart from this if roundabout is provided at said intersection then traffic congestion will be reduced to some extent as well as the halt time of vehicles at intersection will be minimized. As discussed above roundabout has far less conflict points than signalized intersection so by providing designed roundabout pedestrian safety can also be achieved.

\section{REFERENCE}

1. Weiqi wang,et al (2012) "Reseaech on capacity of roundabout in Beijing", Proedia- Social and Behavioral Sciences.

2. Dongxi Zheng, David Anoyce (2012) "Measuring Modern Roundabout Traffic Conflict Exposure", Journal of Transportation Safty\& Security.

3. Au Zong Than, Michael kyte, Hongchao Liu (2009) "Vehicle Tracking and speed measurement at intersection using video detection system",Journal of Transportation Engineering.

4. Said Easa (2006) "Optimizing geometric design of roundabouts: multi-objective analysis “, Canadian journal of Civil Engineering.

5. Rebekka Apartian, Bhuiyan Monwar Alam (2015) "Method of crossing at Roundabouts for visually Impaired pedestrians", Transportation Science and Technology, vol 4.

6. Pavan Kumar Chevuri (2018) "Trucks at Roundabous: A synthesis study", Journal of Transportation Technologies.

7. Kadiyali L.R. (2013) "Traffic Engineering Transportation Planning” Khanna Publisher, Delhi. pp 163 - 184.

8. Y.Bie and Z.liu (2013) "Calibration of platoon dispersion parameter considering the impact of the number of lanes.

9. Indian Road Congress- IRC SP 41 (Special Publication).

10. Indian Road Congress (2010) "Manual of specifications and standards of at grade intersections", pp107-178

11. Douglas W. Harwood, Midwest Research Institute. Martin T. Pietrucha, (2012) Pennsylvania State University, and Kay Fitzpatrick, Texas University. developed, "Design of intersections on divided highways" pp 34-76

12. Ram Kumar.B, Adinarayana.B, Mane Sr Rohith, Aurora's Scientific Technological \&amp (2008); Research Academy released the paper "Analysis of Unsignalized intersection", pp 1-48 